\title{
KOMBINASI ECOPRENEURSHIP DAN SAEMAUL UNDONG SEBAGAI UPAYA PENGURANGAN DEGRADASI HUTAN
}

\author{
Ida Ansharyani ${ }^{1}$, Mastawan ${ }^{1}$, Fachry Abdul Razak Afifi ${ }^{1}$, Eni Hidayati ${ }^{2}$, \\ Sharfina Nabilah ${ }^{2}$ \\ ${ }^{1}$ Komunitas Penjaga Pulau, Sumbawa Besar, Indonesia \\ ${ }^{2}$ Universitas Mataram, Mataram, Indonesia \\ eni.hidayati@unram.ac.id
}

\begin{abstract}
Abstrak: Kawasan hutan di Desa Kelungkung, Kabupaten Sumbawa, Provinsi Nusa Tenggara Barat merupakan wilayah tangkapan hujan yang penting untuk menjaga ketersediaan air minum penduduk Kota Sumbawa Besar. Namun tekanan terhadap hutan semakin tinggi akibat pembukaan lahan untuk pertanian lahan kering. Oleh karena itu, diperlukan upaya untuk mengurangi tekanan terhadap hutan. Tujuan kegiatan pengabdian kepada masyarakat (PKM) ini adalah meningkatkan kapasitas komunitas lokal dalam memulai upaya ecopreneurship guna mendapatkan penghasilan tambahan dan mengurangi tekanan terhadap hutan. Studi pustaka dilakukan untuk mengetahui faktor-faktor pendorong dan penghambat seseorang menjadi ecopreneur. Selanjutnya intervensi dirancang untuk mengatasi faktor penghambat dengan menggunakan nilai-nilai pada konsep Saemaul Undong. Ecopreneuryang dikembangkan dalam PKM ini adalah pengembangan produk bernilai tambah dari komoditas lokal yang dianggap tidak/kurang bernilai ekonomis. Kelompok mitra yang dilibatkan yaitu kelompok Sumbawa Premium. Pendekatan yang dilakukan yaitu fasilitasi proses izin P-IRT dan penyediaan dukungan in-kind berupa peralatan. Selain itu, kelompok juga didampingi dalam pembuatan kemasan dan media promosi dan pemasaran. Produk yang dibuat yaitu selai dari buah-buahan yang tersedia di Desa Kelungkung yaitu selai jambu biji dan selai duwet, serta pengolahan biji mete menjadi mete madu panggang. Pada kegiatan PKM ini, kombinasi ecopreneurship dan konsep Saemaul Undong 2.0 merupakan pendekatan yang potensial untuk digunakan dalam pengabdian kepada masyarakat yang lebih berkelanjutan.
\end{abstract}

Kata Kunci: degradasi hutan, ecopreneur, komoditi lokal, nilai tambah, saemaul undong

\begin{abstract}
Forest areas in Kelungkung Village, Sumbawa District, West Nusa Tenggara Province are important catchment teritories for freshwater and drinking water supply for the residents. However, threat toward forest is increasing due to conversion to dry land farming. Hence, efforts to reduce forest degradation is needed. This community service aimed at increasing local community's capacity to initiate ecopreneurship effort to gain additional income and reduce dreadful impacts on the forest. A literature study was conducted to identify factors that support or hinder the people to be ecopreneur. Then interventions were designed to overcome the barriers by adopting the values of Saemaul Undong concept. The ecopreneurship developed in this program was the development of added-valued products from local products having low economic values. A partner group involved in this program is Sumbawa Premium Group. The approach used was by providing assistance to get the necessary license to disseminate their products to the market (P-IRT license) and key equipments to start the business. In addition, we facilitated the making of the product packaging, promotion materials, and marketing. The products made were guava jam, duwet jam, and roasted cashew nut with honey flavor. In this program, a combination of Ecopreneur and Saemaul Undong 2.0 concept is a potential approach in designing and implementing a more sustainable community service.
\end{abstract}

Keywords: forest degradation, ecopreneur, local commodity, added value, saemaul undong

\section{Pendahuluan}

Konsep Planetary Boundary yang mulai diperkenalkan pada tahun 2009 mendefinisikan batas 9 parameter lingkungan yang tidak boleh dilewati agar manusia dapat hidup dengan aman 
yaitu perubahan iklim, hilangnya keanekaragaman hayati dan kepunahan spesies, berkurangnya lapisan ozon pada lapisan stratosfer, asidifikasi lautan, siklus posfor dan nitrogen, perubahan sistem lahan, penggunaan air tawar, partikel mikroskopis di atmosfer dan polusi dari berbagai material baru seperti mikroplastik, radioaktif, nanomaterial, dll (Rockström et al., 2009). Tim internasional yang terdiri dari 18 ahli dan peneliti mengemukakan bahwa empat dari sembilan parameter tersebut sudah melewati batas yaitu perubahan iklim, kenakeragaman hayati, sistem lahan, dan siklus posfor dan nitrogen (Steffen et al., 2015). Selanjutnya mereka mengindikasikan bahwa melewati batas planetary boundaryakan meningkatkan risiko aktivitas manusia menjadikan bumi semakin tidak layak huni, merusak upaya pengentasan kemiskinan, dan menurunkan tingkat kesejahteraan manusia.

Masyarakat sekitar hutan di Desa Kelungkung, Kabupaten Sumbawa, Provinsi Nusa Tenggara Barat (8,55 LS; 117,33 BT), mayoritas merupakan petani lahan kering. Beberapa persoalan yang dihadapi oleh petani lahan kering antara lain curah hujan yang tidak bisa diprediksi (Hidayati, 2011) dan kesuburan lahan yang terus berkurang (Ansharyani, 2018). Untuk mendapatkan tanah subur, petani sekitar hutan kerap membuka lahan baru yang mengakibatkan berkurangnya tutupan hutan. Berkurangnya tutupan hutan karena pertanian merupakan salah satu penyebab utama terlewatinya batas Planetary Boundary parameter ke 6 yaitu perubahan sistem lahan. Rockström et al. (2009) memberikan batasan untuk parameter ini yaitu sebesar $15 \%$ dari tutupan lahan di bumi dapat dijadikan area pertanian. Dengan semakin meningkatnya populasi manusia, maka resiko semakin memburuknya parameter ini juga sangat besar.

Desa Kelungkung berlokasi di bagian hulu Daerah Aliran Sungai (DAS) Batulanteh. Bagian hulu DAS Batulanteh merupakan wilayah tangkapan hujan yang penting bagi sumber air Perusahaan Daerah Air Minum (PDAM) Kabupaten Sumbawa. Oleh karena itu diperlukan upaya untuk mengurangi tekanan terhadap hutan melalui penyediaan mata pencaharian tambahan yang kreatif dan sesuai dengan kondisi lokal.

Ecopreneur merupakan istilah yang umum digunakan untuk mencakup suatu usaha yang berwawasan lingkungan. Ecopreneur merupakan seseorang yang mampu mengubah masalah lingkungan menjadi peluang bisnis. Bukan hanya menguntungkan bisnis sendiri, seorang ecopreneur juga dapat membantu melestarikan alam melalui aktivitas dan inovasi yang dilakukannya (Toyota Eco Youth, 2018). Ecopreneur adalah seorang wirausaha yang memperhatikan lingkungan dalam menjalankan suatu bisnis usaha mikro kecil, dan turut berusaha memberi dampak positif terhadap lingkungan yang berkelanjutan (Kirkwood \& Walton, 2010).

Berdasarkan penjelasan di atas, tujuan dari kegiatan pengabdian kepada masyarakat (PKM) ini adalah meningkatkan kapasitas komunitas lokal untuk memulai inisiasi ecopreneurship di Desa Kelungkung sebagai salah satu upaya mengurangi tekanan terhadap hutan.

\section{Metode}

Pengabdian kepada masyarakat ini dilaksanakan di Desa Kelungkung, Kecamatan Batulanteh, Kabupaten Sumbawa, Provinsi Nusa Tenggara Barat (Gambar 1). Dengan luas 
wilayah sekitar 17,94 km² dan penduduk sekitar 1530 jiwa, desa ini merupakan desa terpadat (85 jiwa/km2) di Kecamatan Batulanteh (Badan Pusat Statistik Kabupaten Sumbawa, 2019).

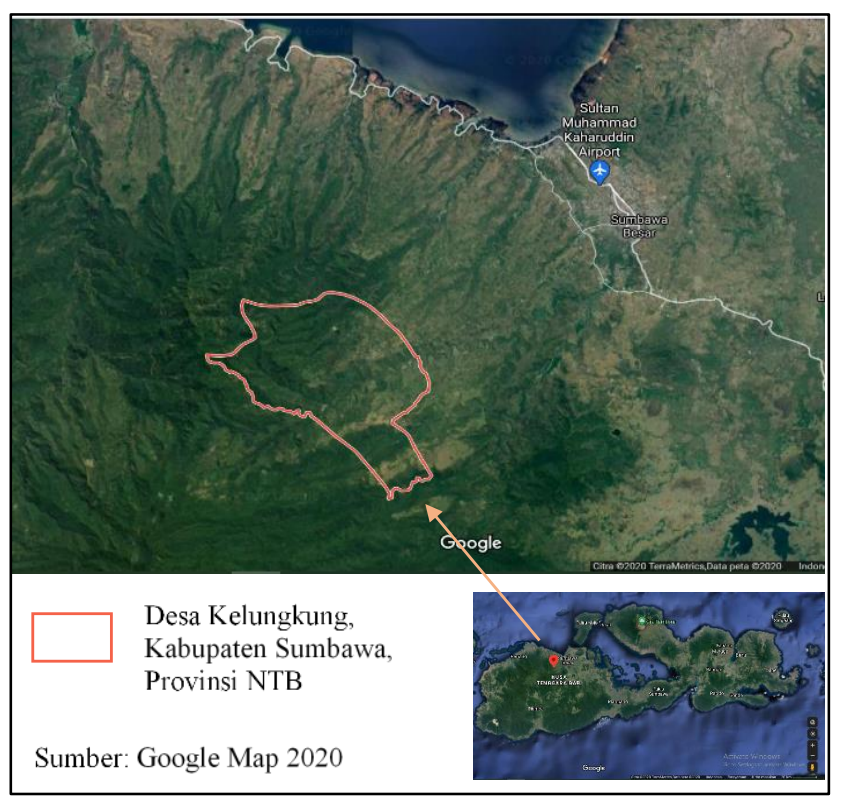

Gambar 1. Lokasi pengabdian

Sebelum mulai menginisiasi upaya ecopreneur, terlebih dahulu dilakukan studi literatur mengenai apa saja faktor penghambat dan pendorong seseorang menjadi ecopreneur. Dari hasil studi literatur, diperoleh beberapa faktor penghambat antara lain (Kirkwood \& Walton, 2010): lack of information (kurangnya informasi), limited knowledge and willingness to share information (terbatasnya pengetahuan dan kesediaan untuk berbagi informasi), lack of awareness (kurangnya kesadaran), dan limited public funding (pendanaan publik terbatas). Selain itu, sulitnya pengurusan P-IRT banyak diungkapkan oleh pelaku UMKM di Nusa Tenggara Barat (Radar Lombok, 2019). Sedangkan faktor pendorongnya antara lain (Kirkwood \& Walton, 2010): green values (nilai lingkungan dalam diri seseorang), gap in the market (celah pasar), making a living (sumber pencaharian), be their own boss, dan passion (ketertarikan).

Untuk menghasilkan perubahan yang positif di tingkat desa, salah satu pendekatan yang digunakan yaitu konsep Saemaul Undong 2.0. Gerakan ini digagas di Korea Selatan pada tahun 1970 yang merupakan kunci keberhasilan pembangunan desa di Korea Selatan (Choi, 2018). Lebih lanjut Choi (2018) menjelaskan bahwa konsep ini terdiri dari lima proses utama yaitu selfhelp - diligence - cooperation - sharing - creativity. Kegiatan PKM ini dirancang dengan mengkombinasikan konsep Saemaul Undong 2.0 dan mempertimbangkan faktor-faktor penghambat dan pendorong ecopreneur.

Berikut ini adalah bagan alir rancangan intervensi yang diterapkan dalam kegiatan PKM ini (gambar 2). Kegiatan yang dilakukan diidentifikasi untuk mengatasi faktor penghambat dengan menerapkan konsep Saemaul Undong 2.0. Misal kegiatan pertama adalah identifikasi potensi lokal $(\mathrm{c}, 1)$. Artinya kegiatan ini mengatasi masalah $\mathrm{c}-$ lack of awareness dengan nilai 1-self help. 


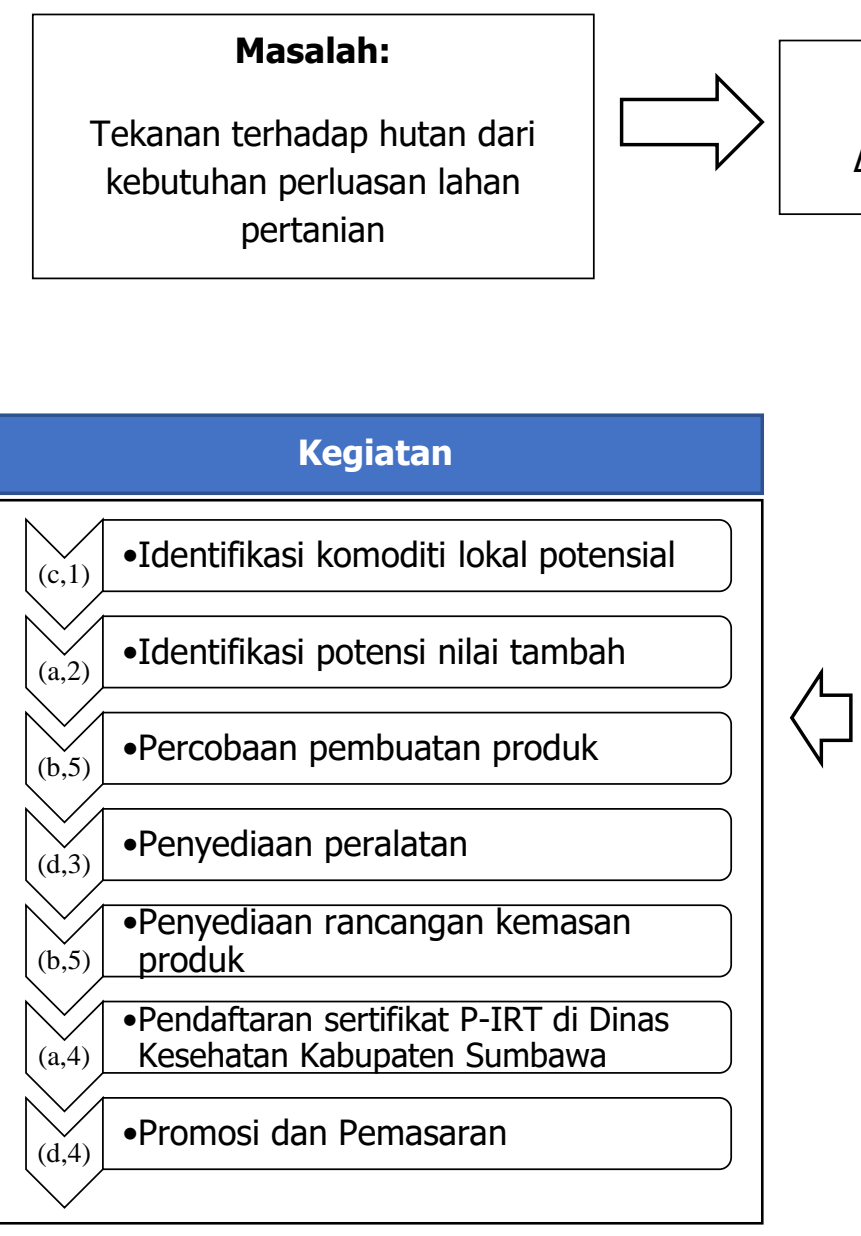

\section{Solusi:}

Ecopreneur
Nilai saemaul undong $\mathbf{2 . 0}$

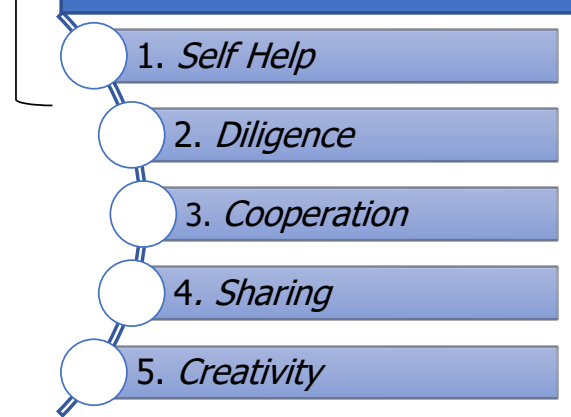

Gambar 2. Bagan alir rancangan intervensi

Penguatan kapasitas petani sekitar hutan untuk meningkatkan nilai komoditas lokal di lokasi pengabdian dilakukan secara holistik dan bertahap dengan tahapan seperti pada Gambar 2. Keseluruhan kegiatan dilaksanakan pada Oktober 2019 - September 2020. Kelompok mitra yang dilibatkan sebagai penerima manfaat yaitu kelompok Sumbawa Premium.

Langkah 1 yaitu identifikasi potensi komoditi lokal. Survei lapangan dilakukan untuk memetakan komoditi lokal berkambium. Tumbuhan tersebut juga harus dapat beradaptasi pada lingkungan yang kering. Beberapa komoditi potensial yang teridentifikasi yaitu jambu biji (Psidium sp.), mete (Anacardium occidentale), juwet (Syzygium cumini), mengkudu (Morinda citrifolia), kemiri (Aleuritas molucanus), kelor (Moringa oleifera), jeruk monte (Citrus hystrix).

Langkah 2 yaitu identifikasi potensi nilai tambah. Identifikasi produk apa yang dapat dihasilkan dari komoditi lokal dilakukan dengan metode studi literatur dan wawancara. Dari hasil studi literatur diketahui bahwa komoditi lokal potensial yang sudah diidentifikasi tersebut memiliki nilai nutrisi yang baik (Parvez et al., 2018). Dengan mengkombinasikan informasi mengenai nilai nutrisi, distribusi dan kelimpahan komoditi, dan keunikan produk, maka diputuskan untuk membuat percobaan dari tiga komoditi yaitu jambu biji, mete, dan juwet. 
Langkah 3 adalah percobaan pembuatan produk. Produk yang dibuat yaitu selai dari buah-buahan yang tersedia di Desa Kelungkung yaitu selai jambu biji dan selai duwet, serta pengolahan biji mete menjadi mete madu panggang. Bahan-bahan yang digunakan adalah bahan-bahan alami (gambar 3) dan tidak menggunakan pengawet dan pewarna. Setelah produk dibuat dan memuaskan dari segi rasa, kelompok Sumbawa Premium difasilitasi untuk mengajukan izin Pangan Industri Rumah Tangga ke Dinas Kesehatan Kabupaten Sumbawa.

Langkah 4 yaitu penyediaan peralatan. Peralatan seperti kompor, panci besar, oven, dan blender disediakan untuk digunakan seterusnya oleh kelompok. Selain itu, kelompok juga diberikan telepon seluler agar kelompok dapat mempromosikan produk mereka melalui media sosial dan mudah berkomunikasi dengan calon pembeli.

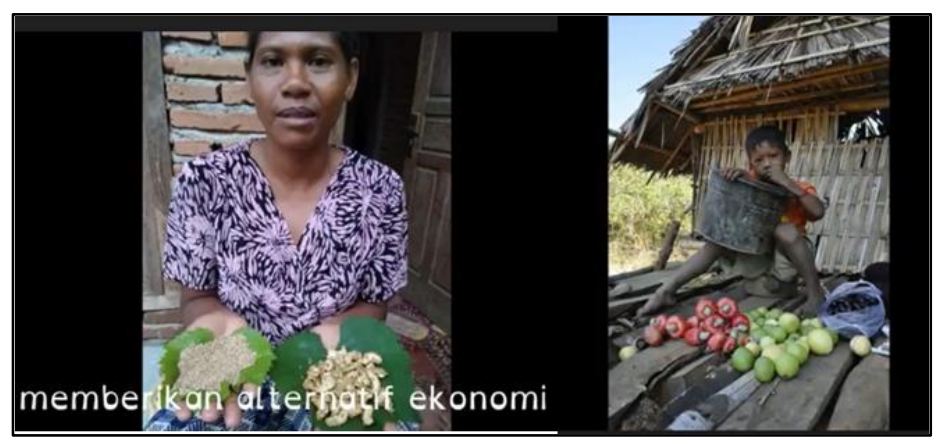

Gambar 3. Bahan lokal

Langkah 5 adalah penyediaan rancangan kemasan dan label produk. Label dan kemasan produk dirancang agar menarik pembeli serta aman bagi produk. Untuk selai, kemasan yang digunakan adalah botol kaca sedangkan untuk mete kemasan yang digunakan adalah kantong kertas. Label dari kemasan sebagaimana nampak pada gambar 4a dan 4b.

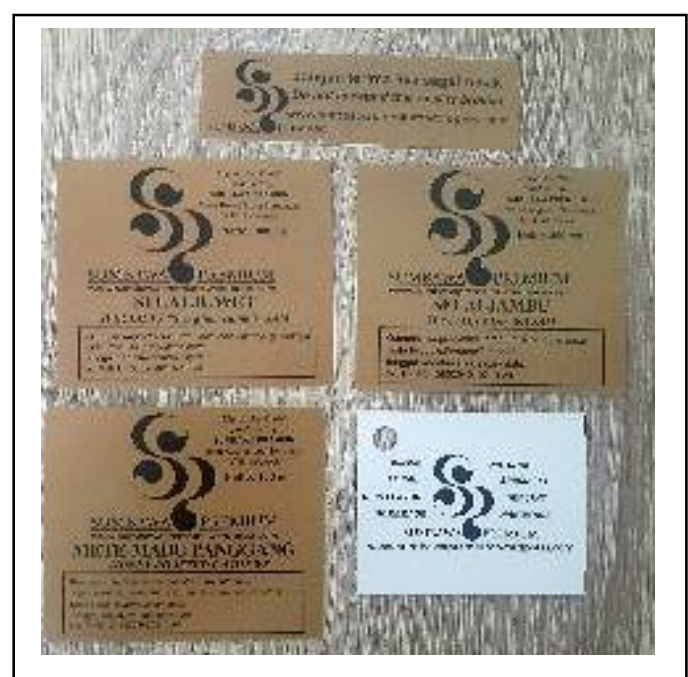

Gambar 4a. Desain label

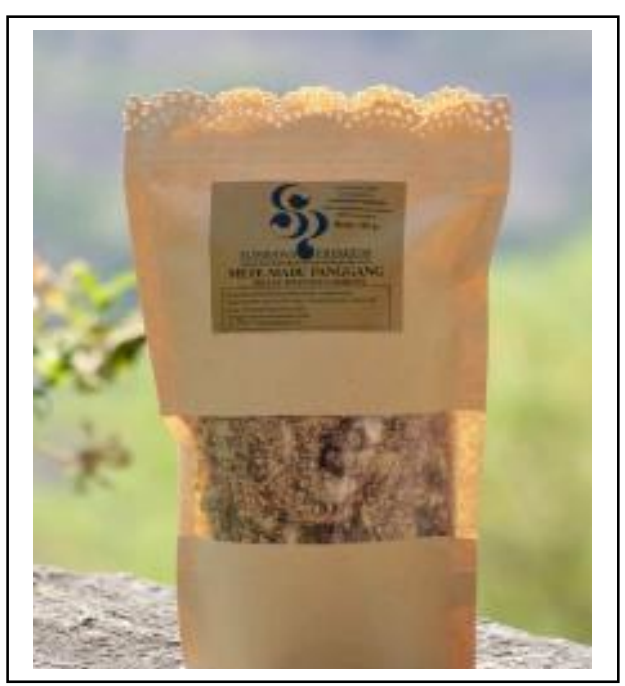

Gambar 4b. Desain kemasan 
Langkah 6 yaitu pengurusan izin P-IRT. Pengurusan izin P-IRT diperlukan oleh UMKM atau usaha skala rumahan yang menjual makanan agar produk yang dihasilkan dapat dipasarkan. Sulitnya pengurusan P-IRT banyak diungkapkan oleh pelaku UMKM di Nusa Tenggara Barat (Radar Lombok, 2019). Oleh karena itu, kegiatan pengabdian yang kami lakukan ini juga mendampingi kelompok hingga mendapatkan sertifikat P-IRT. Langkah yang dilakukan untuk mendapatkan P-IRT mengikuti prosedur yang berlaku seperti yang dilakukan oleh Hutami, et al., (2019).

Langkah 7 yaitu promosi dan pemasaran. Promosi dilakukan melalui media sosial seperti Instagram dan Facebook. Kelompok didampingi dalam pembuatan website, akun Instagram, konten-konten dan foto-foto promosi. Pemasaran dilakukan melalui media sosial dan dititipkan di toko-toko souvenir.

\section{Hasil dan Pembahasan}

Produk yang dihasilkan oleh Kelompok Sumbawa Premium ini menjangkau pasar lokal dan beberapa dari luar kota Sumbawa Besar. Untuk pembeli dari luar kota Sumbawa Besar, produk dikirimkan melalui pos dan biasanya pembeli memperoleh informasi dari media sosial dan informasi dari teman. Konsumen bervariasi mulai dari pemuda-pemudi hingga ibu-ibu. Produk selai sudah terjual sebanyak sekitar 310 botol dengan permintaan tertinggi pada masa idul fitri. Namun penulis belum melakukan kajian lebih lanjut mengenai karakteristik konsumen.

Terkait dengan konsep Saemaul Undong 2.0, pembelajaran yang diperoleh dari kegiatan PKM ini antara lain:

\section{Self Help}

Untuk mendorong timbulnya self-help pada kelompok masyarakat di pedesaan terkadang memerlukan adanya dorongan dari organisasi luar terlebih dahulu sebagai katalisator yang dipandang netral. Terutama untuk isu-isu sensitif seperti pembukaan lahan hutan untuk pertanian. Dalam PKM ini, untuk mendorong self-help, kelompok diajak berdiskusi mengenai persoalan mereka dan mencoba mengidentifikasi asset yang mereka miliki. Dalam PKM ini aset yang difokuskan adalah tanaman yang tumbuh di daerah mereka tetapi masih dianggap bernilai ekonomi rendah.

\section{Diligence}

Dengan mengidentifikasi potensi nilai tambah produk dan praktik membuat produkproduk tersebut, kelompok memperlihatkan kualitas diligenceyang dimiliki. Pada PKM ini, faktor diligence ini didukung dengan penyediaan akses terhadap informasi melalui internet. Dengan modal informasi yang dimiliki, kelompok dapat melakukan percobaan pembuatan produkproduk dari komoditi lokal disekitar mereka.

\section{Cooperation}

Komunitas lokal sekitar hutan di Desa Kelungkung memiliki potensi yang dapat dikembangkan. Namun seperti pada kebanyakan penduduk di pedesaan, mereka juga kesulitan mendapat akses ke permodalan untuk memulai usaha tanpa agunan. Dengan kerjasama, 
pendekatan yang kami lakukan yaitu mendampingi proses izin P-IRT dan menyediakan dukungan in-kind berupa peralatan agar mereka dapat memulai usaha. Seperti pada UMKM lainnya, bantuan in-kind (bukan cash) memberikan kontribusi yang penting bagi pengembangan usaha (Budiman, et al., 2020).

P-IRT diperoleh dari Dinas Kesehatan Kabupaten Sumbawa dalam waktu yang cukup singkat. Petugas dari Dinas Kesehatan juga sangat responsif dan kolaboratif selama proses pengurusan izin P-IRT. Setelah melewati semua prosedur (mulai dari pengisian formulir hingga kunjungan ke industri rumahan dan lulus tes penyuluhan keamanan pangan), P-IRT didapatkan dengan masa berlaku selama 5 tahun sejak 2019 hingga 2024. Nomor P-IRT yang diperoleh yaitu 1085204010210-24. Arti dari 15 digit nomor izin tersebut adalah sebagai berikut (Kepala BPOM, 2012):

a. Digit ke-1 menunjukkan kode jenis kemasan sesuai aturan Badan POM

b. Digit ke-2 dan 3 menunjukkan nomor urut/kode jenis pangan IRTP sesuai aturan BPOM

c. Digit ke-4,5,6,7 menunjukkan kode propinsi dan kabupaten/kota sesuai dengan lampiran dari aturan BPOM

d. Digit ke-8 dan 9 menunjukkan nomor urut pangan IRTP yang telah memperoleh SPP-IRT

e. Digit ke-10,11,12,13 menunjukkan nomor urut IRTP di kabupaten/kota yang bersangkutan

f. Digit ke-14 dan 15 menunjukkan tahun berakhirnya masa berlaku izin P-IRT

Setelah memperoleh P-IRT, produk kemudian dibuat dan dikemas untuk siap dipromosikan dan dipasarkan. Kemasan produk jadi untuk selai jambu, selai juwet, dan mete madu panggang dapat dilihat pada gambar 5 .

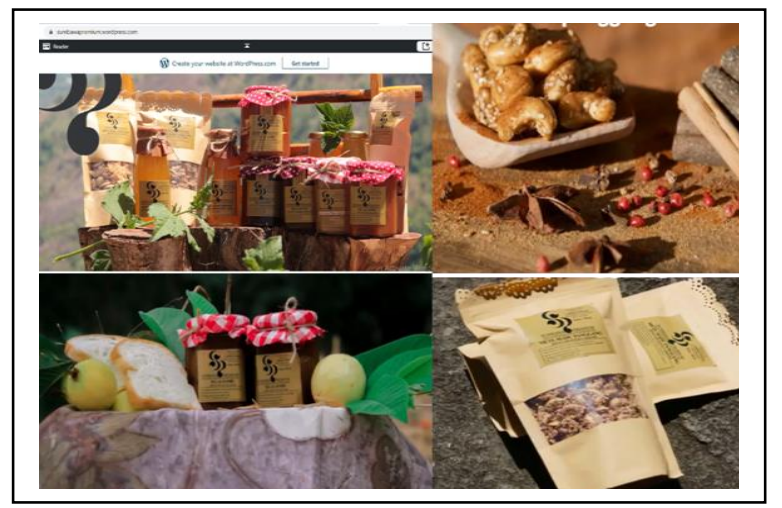

Gambar 5. Produk akhir yang dihasilkan

Sebagai bisnis baru yang cukup kecil di masa pandemi Covid 19, kelompok Sumbawa Premium juga menemui beberapa kendala yaitu turnover atau omset yang masih rendah. Untuk meningkatkan penjualan diperlukan upaya lain yang bisa didukung oleh pemerintah desa melalui dana desa, organisasi nirlaba lain atau universitas. Mengusung bisnisnya sebagai ecoenterpreneurship merupakan peluang yang masih bisa dioptimalkan dengan dukungan dari ahli-ahli ecoenterpreneur. 


\section{Sharing}

Berbagi adalah konsep penting tidak hanya dalam Saemaul Undong 2.0 tetapi juga dalam ecopreneur. Tujuan ecopreneuradalah memperoleh profit yang kemudian bisa digunakan untuk mengurangi persoalan lingkungan yang ada. Salah satu hal yang dapat dilakukan untuk meningkatkan profil mereka sebagai bisnis ramah lingkungan yaitu dengan menyisihkan pendapatan mereka untuk kegiatan rehabilitasi hutan dengan pohon-pohon buah produktif sehingga dapat menjadi bukti nyata kontribusi pembeli terhadap kelestarian hutan. Selain itu pohon-pohon ini juga dapat dipanen buahnya di masa depan.

Kelompok Sumbawa Premium juga sudah mulai aktif mengikuti kompetisi-kompetisi di tingkat kabupaten dan provinsi. Salah satu kompetisi yang diikuti di tingkat provinsi adalah menjadi finalis dalam kegiatan perlombaan International Council for Small Business (ICSB) Nusa Tenggara Barat 2020.

\section{Creativity}

Dalam mempromosikan produknya, kelompok Sumbawa Premium menekankan nilai-nilai lebih dari produknya yaitu produk berkualitas dari komoditi lokal, membantu ekonomi lokal, dan mengurangi degradasi hutan. Media sosial yang digunakan yaitu facebook (sumbawapremium), instagram (@sumbawa.premium), dan website (www.sumbawapremium.wordpress.com). Selain itu, dengan adanya P-IRT, produk juga sudah dapat dititipkan di toko-toko. Pesan lingkungan yang mereka advokasikan berasal dari kearifan lokal Sumbawa yaitu: Kle Tu Sabalong Desa, Na Sarusak Tani Tana, Sanuman Nanta Tu Mudi yang artinya Meskipun Kita Membangun Desa, Janganlah Merusak Tanah dan Lingkungan Kita, Tinggalkan Lingkungan yang Baik Bagi Generasi Mendatang.

\section{Kesimpulan}

Dari hasil kegiatan pengabdian ini dapat disimpulkan bahwa pendampingan dan penyediaan dukungan in-kind perlu dilakukan dari proses identifikasi potensi, perancangan intervensi hingga ke pemasaran produk. Konsep Saemaul Undong 2.0 ini membantu masyarakat dan akademisi untuk merancang intervensi dari suatu masalah secara lebih partisipatif dan kolaboratif. Dengan dana desa yang dimiliki, pemerintah desa dapatmengadaptasi konsep ini dalam upaya pengembangan desanya agar mengurangi tekanan terhadap hutan dan lingkungan. Intervensi-intervensi lainnya dapat dirancang dengan semangat self-help, diligence, cooperation, sharing dan creativity.

Masih banyak komoditi lokal lainnya yang potensial untuk dikembangkan sebagai produk bernilai tambah. Kegiatan pengabdian selanjutnya bisa memikirkan inovasi-inovasi produk lainnya. Penggunaan pestisida yang berlebihan mulai membuat pohon jambu biji yang awalnya banyak tumbuh menjadi berkurang secara signifikan. Kegiatan pengabdian selanjutnya dapat berfokus pada kegiatan pelatihan pembuatan pestisida organik. 


\section{Referensi}

Ansharyani, I. (2018). Barriers to Climate Change Adaptation and Sustainable Livelihoods: Conflicts in Knowledge, Policy and Management of Forests in Batulanteh Watershed, Sumbawa Indonesia [Rutgers, State University of New Jersey]. In ProQuest Dissertations Publishing: https://search.proquest.com/openview/60e13a87838c132fad8a23b7ab13485e/1?pqorigsite $=$ gscholar\&cbl $=18750 \&$ diss $=y$

Kepala BPOM. (2012). Peraturan Kepala Badan Pengawas Obat dan Makanan Republik Indonesia Noor HK.03.1.23.04.12.2205 tahun 2012 tentang Pedoman Pemberian Sertifikat Produksi Pangan Industri Rumah Tangga. Jakarta: BPOM RI. Diakses di:

Badan Pusat Statistik (BPS) Kabupaten Sumbawa. (2019). Kecamatan Batulanteh dalam Angka Tahun 2019. UD Sari Rejeki. ISBN: 978-602-5567-69-8

Budiman, S.A., Ansharyani, I., Hidayati, E., \& Valentino, N. (2020). Penguatan Usaha Mikro dengan Sistem Bagi Hasil bersama LSM di Desa Kertasari, Kabupaten Sumbawa Barat, Nusa Tenggara Barat. Jurnal Pendidikan dan Pengabdian Masyarakat, 3(3), 169-175.

Choi, Oe-Chool (2018). Saemaul Development and Global Saemaul Undong for Community Development. Sue Kenny, Brian McGrawth, and Rhonda Phillips (eds.). The Routledge Handbook of Community Development (pp. 72-86). Routledge.

Hidayati, E. (2011). Farmers' perception of environmental problems: A case study in Batulanteh Watershed, Indonesia [State University of New York]. In ProQuest Dissertations Publishing: https://search.proquest.com/openview/5702b0ccb3553d3a0410a82395356313/1?pqorigsite $=$ gscholar\&cbl $=18750 \&$ diss $=y$

Hutami, R., Amalia, L., Aminah, S., dan Agusta, E. N. (2019). Pendampingan pendaftaran sertifikasi pangan industri rumah tangga (P-IRT) UKM pangan berbasis talas dan nanas Bogor di Kota Bogor. Jurnal Qardhul Hasan. 5, 57-63.

Kirkwood, J., \& Walton, S. (2010). What Motivates Ecopreneurs to Start Businesses?. International Journal of Entrepreneurial Behavior and Research, 16(3), 204-228.

Radar Lombok. (2019). UMKM Pangan Masih Dipersulit Urus Izin P-IRT. https://radarlombok.co.id/umkm-pangan-masih-dipersulit-urus-izin-p-irt.html

Parvez, G. M., Uzzaman, S., Miah Akanda, K., \& Mehjabin, S. (2018). A short review on a Nutritional Fruit: Guava. Open Access: Toxicology \& Research, 1(1), 1-8. http://biocoreopen.org/articles/A-short-review-on-a-Nutritional-Fruit--Guava.pdf

Rockström, J., Steffen, W., Noone, K., Persson, Å., Chapin, F. S., Lambin, E. F., Lenton, T. M., Scheffer, M., Folke, C., Schellnhuber, H. J., Nykvist, B., De Wit, C. A., Hughes, T., Van Der Leeuw, S., Rodhe, H., Sörlin, S., Snyder, P. K., Costanza, R., Svedin, U., ... Foley, J. A. (2009). A safe operating space for humanity. Nature, 461(7263), 472-475. https://doi.org/10.1038/461472a

Steffen, W., Richardson, K., Rockström, J., Cornell, S. E., Fetzer, I., Bennett, E. M., Biggs, R., Carpenter, S. R., De Vries, W., De Wit, C. A., Folke, C., Gerten, D., Heinke, J., Mace, G. M., Persson, L. M., Ramanathan, V., Reyers, B., \& Sörlin, S. (2015). Planetary boundaries: Guiding human development on a changing planet. Science, 3476223). https://doi.org/10.1126/science.1259855

Toyota Eco Youth. (2018). Ecosociopreneur, berbisnis demi lingkungan dan masyarakat (Artikel web). Diakses di toyotaecoyouth.com/news/detail/10/ecosociopreneur-berbisnis-demilingkungan-dan-masyarakat 